\title{
An Evaluation of a Pilot Study of the Personal Tutoring Programme in Improving Skills Development at the University of Trinidad and Tobago
}

\author{
Andrew Hunte ${ }^{1}$, Wasi Z Khan ${ }^{2} \&$ Rohanie Maharaj ${ }^{3}$ \\ ${ }^{1}$ Foundations and Prior Learning Unit, The University of Trinidad and Tobago, O’Meara Campus, Arima, Trinidad \\ ${ }^{2}$ Project Management and Civil Infrastructure Systems, The University of Trinidad and Tobago, San Fernando \\ Campus, Trinidad \\ ${ }^{3}$ Biosciences, Agriculture and Food Technologies (BAFT)/Center of Expertise in Food Security and Sustainability \\ (CEFSS), The University of Trinidad and Tobago, Centeno Campus, Mausica, Trinidad \\ Correspondence: Rohanie Maharaj, Professor, Biosciences, Agriculture and Food Technologies (BAFT)/Center of \\ Expertise in Food Security and Sustainability (CEFSS), The University of Trinidad and Tobago, Centeno Campus, \\ Mausica,Trinidad
}

Received: October 17, 2019

Accepted: February 1, 2020

Online Published: February 18, 2020

doi:10.5430/ijhe.v9n1p280

URL: https://doi.org/10.5430/ijhe.v9n1p280

\begin{abstract}
Personal tutoring provides professional skills development and support to students as they matriculate through their respective university programmes. Recently, there has been a growing trend of students facing academic difficulties in their first year of undergraduate study at the University of Trinidad and Tobago (UTT) which have impacted on student retention rates. This paper shares the experiences of a pilot study of the Personal Tutoring Programme (PTP) launched in term 2 (January to May) of the 2018 academic year, at the UTT where five hundred and thirty-two (532) students along with forty-eight (48) personal tutors (PTs) engaged in activities that promoted academic and social support. During term 2, PTs met with their assigned tutees at least once per week. The evaluation of the PTP in skills development was based primarily on pass rates of term 2 courses in the Certificate of Applied Engineering (CAE) and Bachelor of Applied Science Common Year I (BASc Common Yr I). These programmes are used as entry requirements to specialized diploma and bachelor level programmes at UTT. Within the BASc Common Yr I, there were marked improvements in the Engineering Thermodynamics course while in the CAE programme, there were marked improvements in the Applied Engineering Mathematics II course with 100\% pass rates in two campuses where it was offered. Student feedback was indicative of the positive impact of the PTP which improved students pass rates with engineering courses that traditionally were difficult for them. Overall the PTP contributed to the holistic development of the students.
\end{abstract}

Keywords: personal tutoring, skills development, undergraduate engineering students, university of Trinidad and Tobago

\section{Introduction}

The national University of Trinidad and Tobago (UTT), just fifteen (15) years in existence, continues to make a significant contribution to academic wealth and national development needs of Trinidad and Tobago by promoting holistic education in engineering, science, technology, arts and education. The range of programmes from certificate to doctoral levels continue to produce exemplary graduates who are knowledgeable, innovative and inspired to utilize their learning in creative ways that generate wealth and enhance the quality of life of all citizens of Trinidad and Tobago. However, despite the university's provision of quality education, there are still many students who fail to successfully complete their programme of study. In recent years, there has been a growing trend of students facing academic difficulties particularly in their first year of undergraduate study at the UTT. These academically related issues coupled with a plethora of social challenges such as financing, study habits, and undiagnosed learning disabilities have led to relatively low student retention rates at UTT (Williams, 2016). Student retention, as defined in this study, is the ability of an institution to retain a student from admission through graduation. Another important concept, often used interchangeably with retention, is persistence, which refers to the student's ability to persevere to graduation. Retention statistic is a key metric of a university's success and reflect the overall quality of student learning and intellectual involvement; how well integrated students are in university life; and how effectively the 
institution delivers what students expect and need (Williams, 2016). Students' retention not only play a significant role in their holistic development but in the financial health of the institution. In order to possibly address academic issues and strategically monitor students' performance during their first year, UTT assigned a personal tutor (PT) for each first-year entry-level student. This programme was launched on a pilot phase during term 2 of the 2018 academic year. The UTT is expected to realize an improvement in student pass rates, a more holistic approach to supervising students and be more student-focused from this initiative. In this paper, we present the pilot study of the Personal Tutoring Programme (PTP) and the possible impact on student's performance and retention at UTT.

\section{Personal Tutoring Framework}

The Personal Tutoring Programme (PTP) is an interactive process that focuses on the personal relationship between the student and their personal tutor (PT). The PT will challenge the student to reflect upon his or her personal and/or professional goals in order to enhance his or her academic achievement at UTT, particularly, during the first year of study. In this interactive process, the PT will encourage the student to become more self-aware of his or her strengths, weaknesses, values, interests, academic goals and personal goals.

According to Bettinger and Baker (2011), in their study about students' success in academic mentoring or coaching programmes, they noted that, the key reason students struggle to succeed at university is that they lacked key information and guidance about how to successfully manage their respective university programmes. Moreover, other international and caribbean scholars have identified that students' inability to easily access support services and academic mentorship can impact their successful matriculation throughout their first year of post-secondary education (Swail, 2009; Williams, 2004; Wolff, 2009). In consideration of our current retention rate at UTT, along with the need to provide holistic development to our students, there exists a need for a suitable personal tutoring/coaching model to be integrated into our programmes.

\subsection{Background}

In 2016, the Student Support Services (SSS) of UTT analyzed the retention statistics of students and proposed mitigation strategies (Williams, 2016). According to the analysis, students at UTT experienced many challenges in their first year of university life such as: (a) transition and coping with academic expectations (b) lack of understanding of the nature and demands of their programmes, (c) financial difficulties, (d) lack of skills required to cope at university level and (e) unawareness of support services available to them. Based on the findings of the analysis, the university's administration attempted to address these challenges by proposing the following initiatives within the 2017 academic year:

a. Developing a university culture, policies and processes that foster student persistence and success

b. Enhancing recruitment and admissions processes

c. Expanding preparation and transition programmes and services such as pre-university preparatory academic programmes

d. Strengthening curricular and instructional practices to foster student success

e. Establishing early warning and academic support services

f. Expanding the existing range of students support resources that can foster student's engagement, development, health, academic, and social well-being.

In response to collectively addressing these initiatives, the administration responsible for the 2018 academic year proposed the increased involvement of academic staff through the establishment of a Personal Tutoring Programme (PTP).

\subsection{Roles, Responsibilities and Expectations of the Personal Tutor (PT)}

A PT is a designated full-time faculty member, who will be responsible for the academic mentoring of about 10-15 students and whose main role as a PT is to provide support to students enrolled in the first year of their respective programme. Normally they are instructors in the programmes in which they are assigned tutees and the support, while it is not limited to academics, it includes the provision of guidance on (a) study habits, (b) time management, (c) communication skills, or (d) any skill-set deemed important for academic and social success at UTT. It is possible that the PT will not hold specialized content knowledge, however, they can arrange tutoring for the students through the available instructional support such as remedial classes, or during the office hours of the student's respective instructors. Programme leaders (heads of units) in consultation with Student Support Services (SSS) unit of the UTT, are responsible for providing the required training for faculty to become effective PTs. 
A PT can be considered as the conduit through which students can access services of the SSS of the UTT as shown in Figures 1 and 2. An example of this is where, financial issues can be handled firstly by the PT attaining the necessary information from the student and then alerting or contacting the respective resource personnel to handle the student's issue. Once the contact has been made, the PT will monitor the resolution of the issue and ensure that the student retention is maintained.

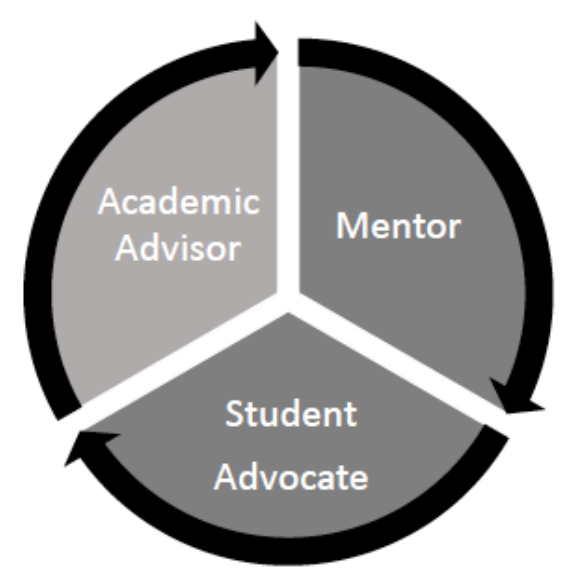

Figure 1. The major roles of a personal tutor at the University of Trinidad and Tobago

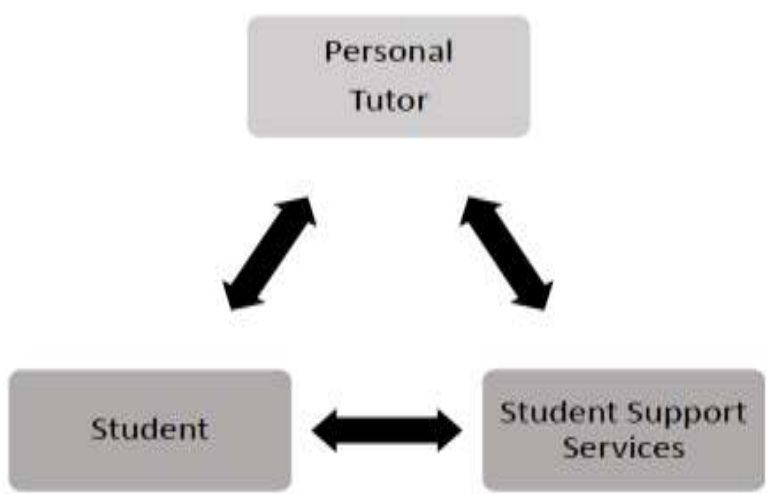

Figure 2. The communicative role of a personal tutor

The main roles of a PT are:

a. Gaining knowledge of students - demographics, performance data

b. Instructing at-risk students

c. Analyzing course outcomes

d. Implementing early alert of student's academic difficulties

e. Academic advising

f. Peer tutoring and organizing instructional support

g. Fostering holistic student development

h. Partnering with Student Support Services (SSS)

PTs must have meetings with students under their care at least four (4) times during the term to monitor student's academic progress. Meetings can be face-to-face, skype, zoom or any acceptable means of communication agreeable between PTs and students. For example, the PT can set up a new skype account under the name: Dr John Doe 
PT@utt.edu. This account will be strictly used for contacting tutees during their tenure at UTT. A PT has the right to discuss students' academic performance with their respective instructors and provide progress reports to the programme leaders during the term. All instructors must provide on request from the PTs, their respective students' in-course assessments such as quizzes or exams. This will facilitate informative assessment of student's progress in their courses. Each PT must submit an electronic report after each scheduled meeting so that SSS can ascertain students' progress and address any concerns regarding the tutee's retention in their programme at UTT.

\subsection{The Role of Student Support Services (SSS)}

Student Support Services (SSS) at UTT facilitates student learning and development through the promotion of opportunities for academic and co-curricular development. Through collaborations with the PT, students can be educated about the available resources of SSS. Students can also gain access to such services and work towards their holistic development at UTT. The SSS counselling unit will provide the necessary on-going training for PTs and provide useful resources such as websites and scholarly articles to help PTs and their tutees understand their roles and expectations for the success of this programme at UTT.

\subsection{Student's Expectations from the Personal Tutoring Programme (PTP)}

During the pilot phase of the programme, the facilitators and researchers through the office of the SSS compiled a listing of expectations of participating tutees in the PTP. The listing covered the areas of academic development, understanding the university's academic regulations and policies, student responsibility and social development and included:

a. Recognition of student's dominant learning style and applications consistent with the prescriptions of such learning styles;

b. Identification of other learning styles and engagement in specific strategies that support their efforts;

c. Implementation of the learning and teaching provided by the PT

d. Adherence to the UTT's regulations, policies and guidelines

e. Adopting self-responsibility, relying on student's internal guidance system of what is right from wrong, and invoking the quality of self-discipline and personal application;

f. Maintaining positive student behaviour and high levels of personal motivation and with students accepting personal responsibility for their own learning, while accessing the various levels of support that may be provided.

PTs used this listing in order to guide the activities that they engaged in during their sessions with assigned tutees. The listing also allowed PTs to design interventions tailored to help tutees meet the expectations and support their individual academic and social development.

\section{Method}

\subsection{The Pilot Project}

Based on the trends in the percentage failure rates of over $30 \%$ in the December (term I) 2018 final examinations, the PTP pilot was implemented in programmes with the highest number of courses showing these failure rates. Table 1 presents the selected programmes and the number of students who participated in this pilot phase of the PTP. In the pilot study, academic staff assigned to Foundations and Prior Learning (FPL) unit and selected Bachelor of Applied Science Common Year I (BASc Common Yr I) instructors served as PTs. Each PT was appropriately oriented about their expected duties. The staff were informed of how their deliverables would be assessed in their teaching workload and performance appraisals. Table 2 presents a summary of the programmes and respective students enrolled in the pilot phase of the PTP and it also summarizes the number of faculty per campus, who participated in the pilot study. Additionally, Table 2 provides the personal tutor to student ratio for each respective campus. A total of forty-eight (48) participants functioned in the role of PTs in the pilot study. Additionally, selected non-FPL staff were incorporated into the pilot PTP. 
Table 1. Academic programs selected for the pilot phase of the personal tutoring program programme

\begin{tabular}{ccccc}
\hline Level & Unit & Course of study & Campus & Student numbers \\
\hline Certificate & All Engineering & CAE & SF & 67 \\
& & & O'M & 20 \\
& & PL & 15 \\
& & JD & 40 \\
\hline Diploma & Information and & CNT & JD & 25 \\
& Communication & & PL & 38 \\
& Technology & SE & JD & 26 \\
& & & PL & 28 \\
& & & SF & 35 \\
& Utilities & & JD & 29 \\
& & & PL & 41 \\
& & SF & 45 \\
\hline Bachelor of Applied & All Engineering & BASc Common Yr I & O'M & 75 \\
\hline Total & & SF & 48 \\
\hline
\end{tabular}

JD: John Donaldson campus; O'M: O'Meara campus; PL: Point Lisas campus; SF: San Fernando campus

CNT: Computer Networking and Telecommunication Engineering, SE: Software Engineering, EEE:

Electrical Electronics Engineering, CAE: Certificate of Applied Engineering, BASc Common Yr I: Bachelor of Applied Science Common Year I

Table 2. Allocation of personal tutors by campus, programme and students and personal tutor:student ratios

\begin{tabular}{cccc}
\hline Campus & Number of students & $\begin{array}{c}\text { Number } \\
\text { of PTs }\end{array}$ & $\begin{array}{c}\text { PT: Student } \\
\text { ratio }\end{array}$ \\
\hline JD & CNT (25), SE (26), EEE (29), CAE (40) & 10 & $1: 12$ \\
Total= 120 & & \\
O'M & $\begin{array}{c}\text { BASc. (48), CAE (20) } \\
\text { Total= 68 }\end{array}$ & 8 & $1: 9$ \\
PL & CNT (38), SE (28), EEE (41), CAE (15), CAE (67) & 18 & $1: 10$ \\
Total 189 & & \\
SF & SE (35), EEE (45), BASc. (75), & 12 & $1: 12$ \\
& Total= 155 & & \\
\hline
\end{tabular}

JD: John Donaldson campus; O'M: O'Meara campus; PL: Point Lisas campus; SF: San Fernando campus

CNT: Computer Networking and Telecommunication Engineering, SE: Software Engineering, EEE:

Electrical Electronics Engineering, CAE: Certificate of Applied Engineering, BASc Common Yr I: Bachelor of Applied Science Common Year I

\subsection{Quality Assurance in Personal Tutoring}

The impact of the PTP on the student experience included: how quickly an intervention took place; and how students were made aware of available support options. Many personal tutoring plans/policies exist only in theory, written into teaching and learning policies, but are not always fully practiced (Calcagno, Walker, \& Grey, 2017; Smith, 2008). The reality is that PTP policies may not be as effective as they could be and are difficult to evaluate unless linked to a quality assurance framework of the institution. An institution-wide evaluation of the quality assurance (QA) in personal tutoring has not yet been carried out at UTT as it was introduced during the 2018 academic year at selected campuses and programmes. However, at the end of the term 22018 academic year, a random sample of students who had participated in the pilot PTP study were invited to participate in an evaluation survey. The PTP evaluation survey questionnaire is shown in Appendix A. The survey included seven open free-text responses and closed questions. 
A major tenet of the evaluation of the effectiveness of the PTP, is fostering a means by which students can provide peer review of their personal tutoring. In considering this integral aspect of QA, it was imperative to have students give meaningful feedback via the evaluation survey in Appendix A. Thus, a major concern was whether students can effectively provide critical feedback or "personal tutoring peer review" of their assigned PT throughout the pilot programme.

\subsection{Issues of Effective Peer Critique}

Some instructors teaching a descriptive course that require students to produce a substantial amount of writing, consider peer review. A well-planned peer review can help students improve their writing skills and learn how to collaborate effectively. The peer review can help students:

- $\quad$ Learn how to formulate and communicate constructive feedback on a peer's work;

- $\quad$ Learn how to gather and respond to feedback on their own work.

A common misstep that many instructors make in approaching peer review is to assume that students already have the required skills (Washington University at St. Louis, 2018). Instead, instructors should approach peer review as an opportunity to teach students peer review skills and enure that students practice them.

Many instructors have reported less than satisfying results. In fact, it is quite common to find that, when asked to participate in peer review, students rush through the peer-review process and offer their peers only vaguely positive comments, such as "I liked your paper," or "Good job," or "Good paper, but a few parts need more work." Furthermore, many students seemed to ignore peer-reviewer's comments on their writing (Washington University at St. Louis, 2018). Therefore, it was crucial that students understood the importance of providing quality peer review and by extension assisted in evaluating the effectiveness of their PT through a "personal tutor peer review" process.

The effectiveness of one-on-one tutoring is of great interest in a variety of fields, including computer-based tutoring programme development, general education research, and training of future teachers. It is well accepted that one-on-one tutoring promotes both greater student learning and increased student motivation to learn compared with traditional, formal classroom teaching and learning settings (Slavin, 1987). However, examination of the research literature on effective tutoring would suggest that this mode of instruction and our approaches to fostering student understanding in large engineering lecture classrooms need not be different as one might assume. In fact, the differences in what instructors choose to say and do, as well as what they choose not to say and do, in each of these settings may be more critical for learning than the setting itself or the numbers of students involved. Therefore, it is essential that within the personal tutoring framework, instructors and PTs be trained with the necessary skill sets to provide personal instructional support to students. During the pilot phase, all PTs were trained via one of the professional development workshops. The training fostered opportunities to develop instructional strategies aligned to various learning styles particularly, during one on one tutoring sessions with assigned personal tutees.

\subsection{Personal Tutoring Programme Academic Impact at UTT}

In February 2018, the UTT officially launched the pilot phase of the PTP. In this initial phase, 532 students along with 48 PTs engaged in activities that promoted academic, social and psychological support. During the term 2 period of the 2018 academic year, PTs within the Foundations and Prior Learning (PFL) unit participated in workshops, which facilitated their training in providing the necessary support for their tutees. Before the workshop, all participants were provided with a workshop guide. All PTs met with their respective assigned tutees at least once per week. To evaluate the possible impact of the PTP, we considered courses or programmes with historically high failure rates. These courses included the Certificate in Applied Engineering (CAE) and the Bachelor of Applied Science Common Year I (BASc Common Yr I) programmes. We also considered the respective courses that had the same instructor over the last two offerings of the course. This ensured QA oversight on the instructional strategies and course content over the comparative periods. The PTs and their assigned students participated in all workshops or personal tutoring training and informational sessions. Students provided some informal feedback to their programme leader about the assistance they received from the PTP at the end of the pilot phase.

Based on the aforementioned factors, we evaluated the pass rates of courses in the CAE and BASc Common Yr I term 22018 academic year. As mentioned, these two programmes are a major entry point for students at UTT, as both programmes offer foundational courses, which are used as entry requirements to specialized diploma and bachelor level programmes at UTT. Table 3 presents the selected programmes and the number of students within the two highlighted programmes, who participated in this implementation pilot phase of the PTP. 
Table 3. Bachelor of Applied Science and Certificate level programmes selected for the pilot phase of the personal tutoring programme

\begin{tabular}{ccccc}
\hline Level & Department & Course of study & $\begin{array}{c}\text { Campus } \\
\text { designation }\end{array}$ & $\begin{array}{c}\text { Student } \\
\text { numbers }\end{array}$ \\
\hline $\begin{array}{c}\text { Bachelor of } \\
\text { Applied } \\
\text { Science }\end{array}$ & All & BASc Common & O'M; & 75 \\
\hline Certificate & All & Yr I & SF & 48 \\
& Engineering & & SF & 67 \\
& & & O'M & 20 \\
& & PL & 15 \\
TOTAL & & JD & 40 \\
\hline
\end{tabular}

JD: John Donaldson campus; O'M: O'Meara campus; PL: Point Lisas campus; SF: San Fernando campus

CAE: Certificate of Applied Engineering, BASc Common Yr I: Bachelor of Applied Science Common Year I

\section{Results and Discussion}

\subsection{Comparison of Pass Rates for Term 22017 and Term 22018}

Tables 4 and 5 summarizes and compares the pass rates of courses in the identified programmes and campuses offered in term 2 of the 2017 academic year to the pass rates of courses offered in term 2 of the 2018 academic year. As shown in Tables 4 to 5 and Figures 3 to 4, within the BASc Common Yr I programme, courses in Engineering Systems Dynamics (DYNA 1001) and Engineering Thermodynamics (THRM1001) at the SF and O'M campuses had improved pass rates with the PTP while only the Engineering Mathematics II (MATH 1002) course offered at the O'M campus had a marginal improved pass rate. For the BASc Common Yr I programme, marked improvements were noted in the Engineering Thermodynamics (THRM 1001) course compared to the rest of the courses offered across the two campuses. It must be noted that classes for both the Electical Systems (ELEC 1001) and the Engineering Thermodynamics (THRM1001) were split into two groups due to the relatively high number of students enrolled at the SF campus only. Overall this was a good achievement in consideration of the previous performance of students in this course.

In the CAE programme, five (5) courses were offered in each of three campuses (JD, PL and SF) while only three (3) courses were offered at the O'M campus. Both the JD and SF campuses offered identical courses in Applied Engineering Communication I (COMM 1013), Applied Engineering Communication II (COMM 1014) and Applied Engineering Mathematics II (MATH 1025). Applied Physics II (PHYS 1006) and Electrical Workshop II (WKST 1014) were only offered at the JD campus. At the PL campus, Applied Engineering Mathematics (MATH 1024) was offered in lieu of the COMM 1013, while, two (2) of the five (5) courses, COMM 1014 and MATH 1025, were offered at all the campuses listed. At the JD campus, marginal improvements in pass rates were noted in three (3) courses (COMM 1013, COMM 1014 and PHYS 1006) while at the PL campus there were marked improvements in three (3) courses (COMM 1014, MATH 1024 and MATH 1025). Additionally, there were also improvements in COMM 1014, MATH 1025 and PHYS 1005 at the SF campus. Of all three (3) campuses where PHYS 1005 was offered, students either maintained or improved performance. On the other hand, students did not improve performance in two (2) courses offered at the JD and O'M campuses respectively. Overall there were marked improvements in Mathematics with a 100\% pass rate at both the SF and PL campuses respectively. 
Table 4. A comparison of pass rates for courses in the Bachelor of Applied Science Common Year I (BASc Common Yr I) programmes during term 2 of the 2017 and 2018 academic year respectively

\begin{tabular}{|c|c|c|c|c|c|}
\hline Programme & $\begin{array}{l}\text { Campus } \\
\text { location }\end{array}$ & Courses & Course title & $\begin{array}{c}\% \text { Pass } \\
\text { term } 2 \\
2017\end{array}$ & $\begin{array}{c}\% \text { Pass } \\
\text { term } 2 \\
2018\end{array}$ \\
\hline \multirow{3}{*}{$\begin{array}{c}\text { BASc } \\
\text { Common Yr I }\end{array}$} & SF & $* *$ DYNA1001 & Engineering Systems Dynamics & 70.1 & 94.81 \\
\hline & & ELEC1001 & Electrical Systems & 89.81 & $\begin{array}{l}67.50(\text { Group } 1) \\
51.10(\text { Group } 2)\end{array}$ \\
\hline & & $\begin{array}{c}\text { LFSC1002 } \\
\text { MATH1002 } \\
\text { **THRM1001 }\end{array}$ & $\begin{array}{c}\text { Life Sciences } \\
\text { Engineering Mathematics II } \\
\text { Engineering Thermodynamics }\end{array}$ & $\begin{array}{c}100 \\
97.75 \\
42.86\end{array}$ & $\begin{array}{c}100 \\
94.74 \\
72.97(\text { Group 1) } \\
56.76(\text { Group } 2)\end{array}$ \\
\hline \multirow[t]{5}{*}{$\begin{array}{c}\text { BASc } \\
\text { Common Yr I }\end{array}$} & O’M & *DYNA1001 & Engineering Systems Dynamics & 97.44 & 100 \\
\hline & & ELEC1001 & Electrical Systems & 88 & 84.21 \\
\hline & & LFSC1002 & Life Sciences & 86.36 & 86.96 \\
\hline & & *MATH1002 & Engineering Mathematics II & 95.12 & 100 \\
\hline & & **THRM1001 & Engineering Thermodynamics & 56.82 & 86.49 \\
\hline
\end{tabular}

The courses with one asterisk indicate a marginal increased pass rate from 2017 to 2018

The courses with two asterisks indicate a substantial increased pass rate from 2017 to 2018

JD: John Donaldson campus; O'M: O'Meara campus; PL: Point Lisas campus; SF: San Fernando campus 
Table 5. A comparison of pass rates for courses in the Certificate of Applied Engineering (CAE) programmes during term 2 of the 2017 and 2018 academic year respectively

\begin{tabular}{|c|c|c|c|c|c|}
\hline Programme & $\begin{array}{l}\text { Campus } \\
\text { location }\end{array}$ & Courses & Course title & $\begin{array}{c}\% \text { Pass } \\
\text { term } 2 \\
2017\end{array}$ & $\begin{array}{c}\text { \% Pass } \\
\text { term } 2 \\
2018\end{array}$ \\
\hline \multirow[t]{5}{*}{ CAE } & \multirow[t]{5}{*}{ JD } & *COMM1013 & $\begin{array}{l}\text { Applied Engineering } \\
\text { Communication I }\end{array}$ & 77.78 & 82.05 \\
\hline & & *COMM1014 & $\begin{array}{l}\text { Applied Engineering } \\
\text { Communication II }\end{array}$ & 92.50 & 100 \\
\hline & & MATH1025 & $\begin{array}{l}\text { Applied Engineering } \\
\text { Mathematics II }\end{array}$ & 75.86 & 75 \\
\hline & & *PHYS1006 & Applied Physics II & 87.50 & 94.12 \\
\hline & & WKST1014 & Electrical Workshop II & 97.62 & 97.06 \\
\hline \multirow[t]{5}{*}{ CAE } & \multirow[t]{5}{*}{ PL } & **COMM1014 & $\begin{array}{l}\text { Applied Engineering } \\
\text { Communication II }\end{array}$ & 48 & 87.50 \\
\hline & & **MATH1024 & $\begin{array}{l}\text { Applied Engineering } \\
\text { Mathematics I }\end{array}$ & 61.90 & 86.36 \\
\hline & & **MATH1025 & $\begin{array}{l}\text { Applied Engineering } \\
\text { Mathematics II }\end{array}$ & 76.47 & 100 \\
\hline & & PHYS1005 & Applied Physics I & 75 & 75 \\
\hline & & WKST1014 & Mechanical Workshop I & 100 & 100 \\
\hline \multirow[t]{5}{*}{ CAE } & \multirow[t]{5}{*}{ SF } & COMM1013 & $\begin{array}{l}\text { Applied Engineering } \\
\text { Communication I }\end{array}$ & 86.67 & 84.21 \\
\hline & & *COMM1014 & $\begin{array}{l}\text { Applied Engineering } \\
\text { Communication II }\end{array}$ & 80.77 & 94.44 \\
\hline & & **MATH1025 & $\begin{array}{l}\text { Applied Engineering } \\
\text { Mathematics II }\end{array}$ & 76.00 & 100 \\
\hline & & *PHYS1005 & Applied Physics I & 44.44 & 55.56 \\
\hline & & WKST1014 & Mechanical Workshop I & 100 & 100 \\
\hline \multirow[t]{3}{*}{ CAE } & \multirow[t]{3}{*}{ O’M } & COMM1014 & $\begin{array}{l}\text { Applied Engineering } \\
\text { Communication II }\end{array}$ & 83.87 & 80.95 \\
\hline & & MATH1025 & $\begin{array}{l}\text { Applied Engineering } \\
\text { Mathematics II }\end{array}$ & 68.18 & 64 \\
\hline & & **PHYS1005 & Applied Physics I & 51.43 & 78.26 \\
\hline
\end{tabular}

The courses with one asterisk indicate a marginal increased pass rate from 2017 to 2018

The courses with two asterisks indicate a substantial increased pass rate from 2017 to 2018

JD: John Donaldson campus; O'M: O'Meara campus; PL: Point Lisas campus; SF: San Fernando campus 


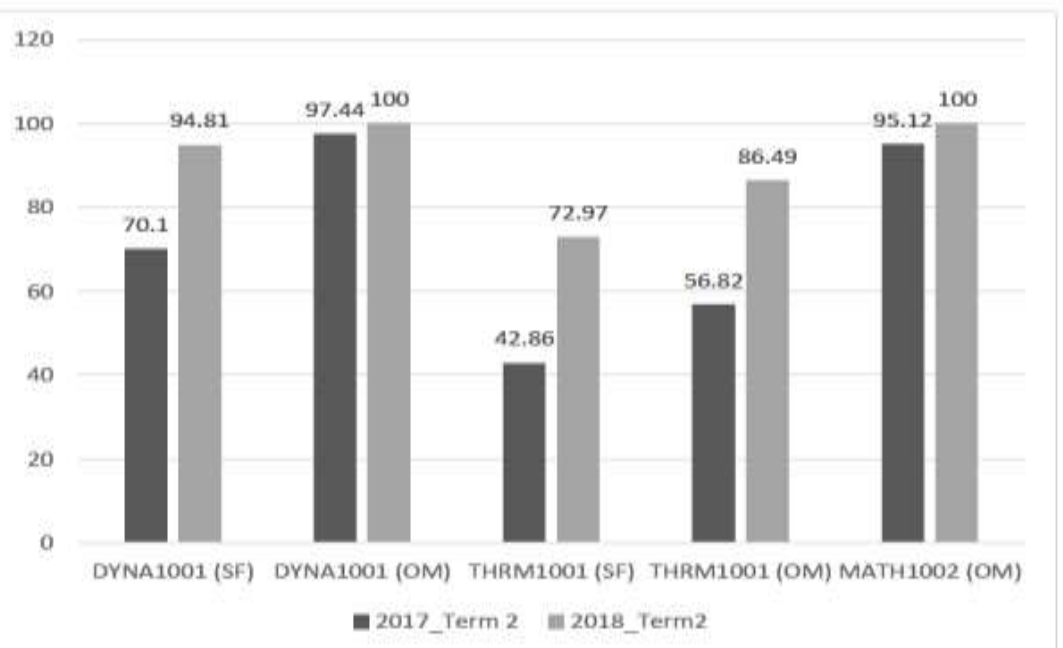

Figure 3. Comparative analysis of the percentage pass rates of the Bachelor of Applied Science Common Year I

(BASc Common Yr I) courses during term 2 of the 2017 and 2018 academic year respectively

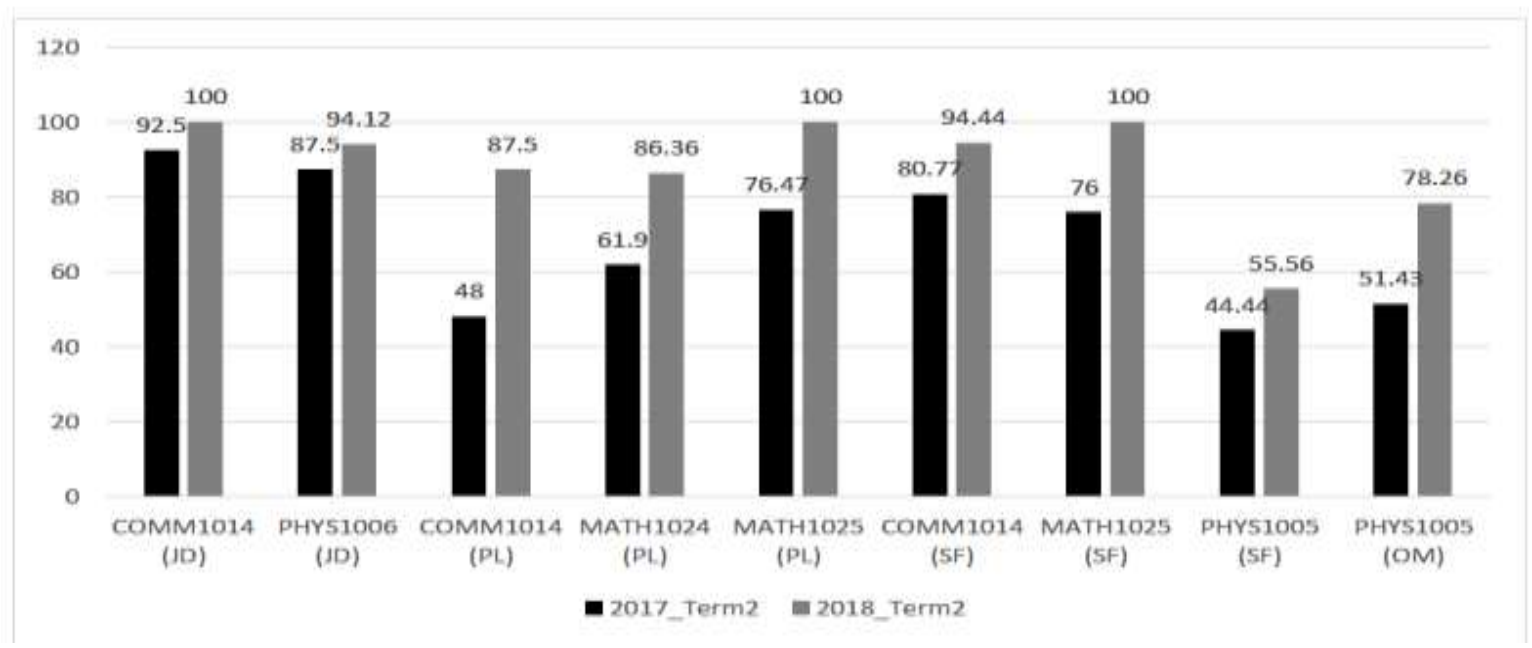

Figure 4. Comparative analysis of the percentage pass rates of the Certificate in Applied Engineering (CAE) courses during term 2 of the 2017 and 2018 academic year respectively

\subsection{Student Feedback}

In order to evaluate the effectiveness of the PTP from a student's perspective, we administered an evaluative survey to participating students in the pilot phase. Within this survey, we asked students their opinions about their experiences with the programme. We also inquired about their expectations and possible impact of the programme on their academic performance, social well-being and overall motivation to progress in their programme of study.

The analysis of PTP evaluation survey indicated that $48 \%$ of students, found the PTP helpful in academic areas such as study habits, learning styles, assistance for difficult classes, and motivational support to succeed; $36 \%$ found it helpful in social areas like personal relationships, family relationships, and financial relationships; and $16 \%$ found it helpful in making decisions for selecting suitable courses for their respective academic programmes. Most students commented that they found their tutor more approachable than the assigned instructor for their courses.

According to several students who provided the feedback, the following quotes are indicative of the possible impact of the PTP coupled with new pedagogies instituted by instructors. Please note pseudonyms were used for the students.

John (CAE): My personal tutor helped me organize my studying skills and helped me remain focused this semester. 
Tisha (BASc Common Yr I): Our personal tutor introduced us to an exercise which determined our learning style. I think this was my breakthrough... I realized my strengths and worked on my weaknesses and I felt more confident and motivated this semester and hopefully my grades will be better.

Nalini (BASc Common Yr I): Initially this semester was really tough, with Thermo, Maths and Elec. However, when I met with my PT (Personal Tutor) they helped me gain extra assistance for these courses and also helped organized study groups that motivated me and helped especially with Thermo and I began to really understand the material.

Shelly (CAE): Well I was a bit apprehensive about meeting my personal tutor, however after meeting with her at our first session, she spent a while helping me work through some personal issues that affected my performance at school. After getting the help I needed through the counsellor, she continued to assist me and I changed my studying habits, got extra tutoring and even got my instructor to assist me with difficult stuff I did not understand in class. I think this was a good thing and it really helped this semester.

Kerry (BASc Common Year I): My PT helped me when I needed it with Thermo and Elec and even directed me to Mathematics Remedial Lab for additional tutoring sessions in Math. This was the best thing, it really helped me out.

The above quotes are indicative of the possible positive impact of the PTP. Despite challenges such as students' inability to attend sessions and insufficient support to deal with psychological and social issues, the PTP to some extent helped students with courses that traditionally were deemed difficult for them. The feedback results suggested that the PTP can build and/or improve staff-student relationships.

\section{Conclusion}

The evaluation of the impact of the PTP in skills development was based on the comparison of pass rates of courses in the Certificate of Applied Engineering (CAE) and Bachelor of Applied Science Common Year I (BASc Common Yr I) term 2 courses over the 2017 and 2018 academic year respectively. Within the BASc Common Yr I, there were marked improvements in the Thermodynamics course across all three campuses. In the CAE programme, there was marked improvements in the Applied Engineering Mathematics II course with a 100\% pass rate at two campuses where it was offered. The feedback from students was indicative of the possible impact of the PTP coupled with new pedagogies instituted by instructors and was viewed as in line with student's expectations. The PTP to some extent helped students with courses that traditionally were difficult for them. The analysis of PTP evaluation survey suggested that around $84 \%$ of students found the PTP helpful in academic and in social areas. In response to the survey question of students' recommendations concerning formalization of peer tutoring, the majority of students surveyed recommended formalization.

\section{Acknowledgements}

The authors wish to thank the President of the UTT, Professor Sarim Al-Zubaidy for his leadership in spearheading the PTP. Appreciation goes out to to all the first-year undergraduate students as well as academic and support staff at the UTT who participated and supported the pilot phase of the PTP during the 2018 academic year.

\section{References}

Bettinger, E. \& Baker, R. (2011). The effects of student coaching in college: An evaluation of a randomized experiment in student mentoring. Stanford, CA: Stanford University School of Education. NBER working paper, 16881(I21) https://doi.org/10.3386/w16881.

Calcagno, L., Walker, D. \& Grey, D.J. (2017). Building Relationships: A Personal Tutoring Framework to Enhance Student Transition and Attainment. Student Engagement in Higher Education Journal, 1(2), 88-89. http://ray.yorksj.ac.uk/id/eprint/2294/.

Slavin R.E. (1987). Cooperative learning and cooperative school. Educational Leadership, 45, 7-13.

Smith, E. M. (2008). Personal tutoring an engineering subject centre guide. The Higher Education Academy,

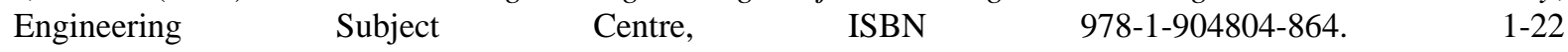
https://s3.eu-west-2.amazonaws.com/assets.creode.advancehe-document-manager/documents/hea/private/perso nal-tutoring_1568036842.pdf.

Swail, W. S. (2009). Graduating at-risk students: a cross-sector analysis. Imagine America Foundation, 1-36. https://educationalpolicy.org/wp-content/uploads/2019/06/GraduatingAtRiskStudents.pdf

Washington University at St. Louis, The Teaching Centre, (2018). Using peer review to help students improve their writing, www.teachingcenter.wustl.edu/resources/writing-assignments-feedback/. 
Williams, H.A. (2004). Some key forces impacting on higher education-the Caribbean perspective. The Association of Caribbean Higher Education Administrators (ACHEA) annual conference. https://www.acheacaribbean.org/sites/default/files/Horace\%20Williams\%20.doc.

Williams, L. (2016). Student Retention and Success at the University of Trinidad and Tobago. Student Support Services of the University of Trinidad and Tobago. 1-39. https://utt.edu.tt/accreditation/2017/R-077\%20Presentation\%20Retention\%20and\%20Student\%20Success\%20P aper\%20for\%20AC.pdf.

Wolff, L. (2009). Challenges and opportunities for postsecondary education and training in Barbados, Bahamas, Guyana, Jamaica, and Trinidad \& Tobago. In: Raby R.L., Valeau E.J. (eds) Community College Models. Springer, Dordrecht, 173-195. https://link.springer.com/chapter/10.1007/978-1-4020-9477-4_11\#citeas.

\section{Appendix A \\ PERSONAL TUTORING EVALUATION SURVEY \\ INSTRUCTIONS}

\section{Dear Student}

We thank you for your participation in the pilot phase of our Personal Tutoring Programme. We wish to invite you to provide us with a brieffeedback about your experiences during this integral phase of the programme. Responses will be kept anonymous in order to adhere to ethical standards for quality assurance of student-support initiatives at UTT.

Table A. Survey on the effectiveness of the pilot personal tutoring programme

Questions Answers

1. What were your initial thoughts about the Personal Tutoring Programme?

2. What aspects of your student life, was the programme most helpful?
Tick as applicable

( ) Academic - Studying Habits

( ) Academic- Learning Styles

( ) Academic- Additional tutoring or assistance for difficult classes

( ) Academic-Motivational support to succeed

( ) Social-Personal Relationships

( ) Social- Family Relationships

( ) Social- Financial Relationships

Other

3. Based on your answer above, what specific role did your Personal Tutor play in assisting you?

4. What expectations do you have if you continued with the Personal Tutoring Programme?

5. What recommendations could you offer to meet your personal and academic needs if you continued in this programme?

6. Did you also receive informal peer tutoring (any or few sessions) during the pilot phase of our Personal Tutoring Programme? If yes, how many sessions? Did you find these helpful?

7. What recommendations could you offer with regards to peer tutoring if formalized by the UTT? 